\title{
The effect of cycle lanes on the proximity between motor traffic and cycle traffic
} John Parkin ${ }^{1}$ and Ciaran Meyers ${ }^{2}$

1 University of Bolton, Deane Road, Bolton, BL3 5AB, UK, j.parkin@bolton.ac.uk Tel.: +44 (0)1204 903027, fax: +44 (0)1204 399074. Corresponding Author.

2 Arup, Admiral House, Rose Wharf, 78 East Street, Leeds, LS9 8EE Ciaran.meyers@arup.com

\begin{abstract}
An experiment collected proximity data of motor traffic overtaking cycle traffic on roads with and without cycle lanes using an instrumented bicycle. The work enhances previous research which has considered the riding position of the cyclist and whether or not the cyclist was helmeted, while controlling for vehicle type.
\end{abstract}

The analysis shows that significantly wider passing distances are adopted by motorists in the condition without a 1.45 metre cycle lane, with posted speed limits of 40mph and 50mph with a 9.5 metre wide carriageway. These findings were not replicated for a similar width road with a posted speed limit of 30mph and a 1.3 metre cycle lane.

The results suggest that in the presence of a cycle lane, drivers may be driving within the confines of their own marked lane with less recognition being given to the need to provide a comfortable passing distance to cycle traffic in the adjacent cycle lane.

\section{Keywords}

Risk, bicycle, bicycle facility. 


\section{$1 \quad$ Background}

Cycling has environmental, social, energy and congestion benefits through reduced motor vehicle use and confers health benefits on the user. However, the perceived risk of cycling is a deterrent to its wider uptake, as discussed in, for example Henson et al. (1997), Davies et al. (1997) and Gardner (1998). Routes for cycle traffic include every part of the highway network (apart from, for example, motorways, which are restricted to motor traffic use) and other off-highway routes which may form convenient shorter routes between parts of the highway network (such as permissive routes across, for example, parks and other open spaces). Important considerations in the promotion of cycling are the detailed design of facilities which may be constructed within the highway specifically for cycle traffic, and the effect of the general conditions which obtain as a result of motor traffic.

A frequent measure of first resort adopted by highway authorities to create facilities for cycle traffic is the painting of a white line to delineate a lane within the carriageway for cycle traffic. In the United Kingdom, such a line may be broken and indicate an advisory cycle lane. It is not illegal for motor traffic to cross such a line and enter the lane. Alternatively a solid white lane may be painted, and, supported by a traffic regulation order, has the effect of making it illegal for motor traffic to travel in the cycle lane.

Cycle lanes may offer a greater degree of separation between the cyclist and the motorist. They may also: usefully direct cycle traffic to the most appropriate position within the carriageway; provide a legal means for cycle traffic to undertake motor 
traffic in queues approaching junctions; provide a degree of continuity and conspicuousness of routes for cycle traffic (Lancashire County Council, 2005). However, as cycle traffic may wish to carry out a variety of manoeuvres within the carriageway, then the presence of a cycle lane may adversely affect the way cyclists use the carriageway, for example, feeling unnecessarily inhibited in moving to the right of a motor traffic lane when carrying out a right turning manoeuvre (left hand rule of the road). Motorists may also wrongly assume that the presence of a cycle lane means that the remaining parts of the carriageway will be free of cycle traffic.

The experience of one of the author's in training UK traffic engineers indicates that Dutch cycle design guidance is often regarded as being the most appropriate guidance available for western countries. This may be based on the false notion that high bicycle usage in The Netherlands is entirely due to high design standards and implementation. There could be many other explanations for high levels of use in The Netherlands including a long history of a culture of cycling. The guidance (CROW, 1993 and 2006) does, however, helpfully differentiate between highway cross-sections as follows: 'spacious', which allow motor traffic and cycle traffic to pass each other comfortably without encroaching into oncoming traffic in the adjacent lanes of an undivided carriageway; 'tight', which are so narrow as to require cycle traffic to follow motor traffic and vice versa; and 'critical', which are some way between 'spacious' and 'tight' and may create the most risky situations because overtaking may occur, but within a carriageway which is not sufficiently wide to allow this to happen comfortably. 
Dutch research (CROW, 2006) shows that motorised traffic will nearly always pass cycle traffic when the bicycle to motor vehicle distance is 0.85 metres or greater. At 30mph, and where the overall width permits, the passing distance is typically around 1.05 metres. According to the Federal Highway Administration (FHWA, 1975), such a clearance produces a lateral force of under 9 Newtons (2lb). While this force may be relatively low and less than the force under normal service braking, the fact that it is induced in the cyclist by the actions of others (the passing traffic), then, from a psychological point of view, this may exceed a level deemed comfortable. The passing dimensions are usefully depicted in cycle guidance prepared by Lancashire County Council (LCC, 2005) as shown in Figure 1 for a carriageway 8.5 metres wide.

[Insert Figure 1 here]

A wider carriageway of 9.5 metres, and assuming equal gaps between motor vehicle and bicycle and motor vehicle and motor vehicle, suggests a passing distance of 1.38 metres.

With a significant presence of Heavy Goods Vehicles of width 2.6 metres, the carriageway width would need to be 10.1 metres wide. The Dutch advice has also been carried through into recent current United Kingdom guidance (DfT, 2008), which suggests ideal total minimum widths for overtaking on a carriageway with a speed limit of 30mph (48kph) of 4.3 metres, or 5.05 metres with significant numbers of heavy goods vehicles. 
The new UK guidance suggests cycle lanes should be 2 metres wide on busy roads or where traffic is travelling in excess of $40 \mathrm{mph}(64 \mathrm{kph})$, but that 1.5 metre lanes may generally be acceptable on roads with a $30 \mathrm{mph}$ speed limit. The guidance notes that cyclists may need to move away from the kerb to avoid surface hazards and this may 'give motorists misplaced confidence to provide less clearance while overtaking than they would give in the absence of a cycle lane'. This assertion has potentially serious implications, particularly for narrower cycle lanes, and is tested by the research presented here.

Most Northern European countries assume driver liability in collisions with pedestrians and cycle traffic for insurance purposes, with the burden of proof falling on the driver to prove that he or she was not liable. This is sometimes (inaccurately) referred to as 'strict liability', and does not obtain in the UK. Also, the provision of cycle lanes in the UK does not alter the legal ability of cycle traffic to place itself in the carriageway in any location which is reasonable, based on its intended future path. This is, vice versa, not always the case in other Northern European countries. Provision of cycle lanes in the UK could be coupled with inappropriate expectations on behalf of cycle lane installers and motor vehicle users that cycle traffic will only use cycle lanes. Hence this may create a legal situation where it is deemed that drivers of motor traffic vehicles could reasonably expect to encounter cycle traffic only in a cycle lane, where present, and indeed change for the worse a situation where the cycle traffic does not even have the protection of strict liability. The research assists in understanding the nature of behaviour with respect to cycle lanes and begins to fill a gap caused by the absence of accident data specifically concerning cycle lanes and their performance. 
The data collected for the analysis presented here were obtained using an instrumented bicycle to measure the passing distance of vehicles relative to a cyclist along six sections of road. The sections have posted speed limits of 30mph, 40mph and 50mph and were sub-divided into sections with and without cycle lanes. Section 2 reviews previous research in the field. Section 3 describes the methodology, Section 4 presents an analysis of the results. A discussion of the results is presented in Section 5 and Section 6 draws conclusions.

\section{Previous research}

Motor traffic passing a cyclist exerts a lateral force because of the air turbulence created. The Federal Highway Administration report (FHWA, 1975) suggest a tolerance limit is defined as 16 Newtons (3.5lbs), equivalent to heavy goods vehicle traffic travelling at $50 \mathrm{mph}, 1.2$ metres from the cyclist. This is a little less than the force experienced during normal service braking.

Considering the physical presence and effect of traffic in a psychological way, Sorton and Walsh (1994) showed that cyclists could recognise aspects of the mental effort of cycling as being related to levels of traffic volume, motor vehicle speed and lane width. Landis et al. (1997) invited 150 cyclists to ride a 17 mile test course in Tampa, Florida with thirty segments of road displaying different characteristics and found that the 
square of the lane width together with other functions of traffic volume, number of lanes, speed, composition, the land form and number of accesses, and pavement surface condition summed to approximate the respondents' six point scale rating of the bicycle 'level of service'. Volume and speed of general traffic were shown to have the greatest contribution to level of service ( 1 is best, 6 is worst). The coefficient for lane width in their model is negative, and suggests that for an increase in width from 3.65 metres of 300 millimetres, the level of service will improve by only 0.125 .

Harkey et al. (1998) used 67 video clips lasting 40 seconds of cycling in various conditions with varying lane widths, motor vehicle speeds, traffic volumes and presence or absence of cycle lanes varying in width from 0.92 metres to 2.44 metres. Their work suggests that a similar six point scale is linearly related to both the width of the cycle lane and the width of the carriageway lane adjacent to the kerb, with a 300 millimetre change in cycle lane width being equivalent to a change in the score of 0.123 and a 300 millimetre change in the carriageway lane width being equivalent to a change in score of 0.149 in the range 3.0 metres to 4.7 metres.

The Federal Highway Administration reviewed the operation and safety of similar sections of route with and without cycle lanes (FHWA, 1999) and found significantly higher rates of conflict between cycle traffic and motor traffic at sites with bikes lanes as compared to sites without, although the rates were small compared with rates with and without cycle lanes on the approaches to junctions. 
In the United Kingdom, Guthrie et al. (2001) attempted to create an index of ‘cyclability’ on a ten point scale (1 bad for cycling, 10 very good for cycling) based on cyclists’ assessment of road and traffic conditions. Fifty-one cyclists rode a 9.2 kilometre route comprising eleven links which were generally non-urban in nature and the sample was biased towards male frequent cyclists. Lane width was included as a linear parameter in the model and contributes 1.03 times the lane width to the cyclability score, a higher proportion than estimated by Landis et al. (1997) and Harkey et al. (1998). In addition, separate 'safety', 'effort' and 'pleasure' ratings were considered and lane width was found to correlate significantly $(\mathrm{p}<0.001)$ with safety $(-$ $0.46)$ and pleasure (-0.42).

In a simulated environment, Basford et al. (2002) found that the provision of cycle lanes appears to increase driver confidence and hence risky behaviour such as higher speeds and less speed reduction when a cyclist is encountered.

Stone and Broughton (2003) tabulate incidence and fatality rates for cycling accidents during 1990-1999 from over 30,000 accidents reported using the United Kingdom STATS19 road accident reporting mechanism. They note with interest the much greater fatality rate for cyclists hit from the rear than from the front.

As part of work for the Warrington Cycle Campaign, Owens (2005) asserts from photographic evidence alone that cycle lanes have the effect of reducing overtaking distances, suggesting a demand for further knowledge and understanding about overtaking distances amongst the cycling community. In a survey using an instrumented 
bicycle on roads in Bristol and Salisbury, Walker (2007) found that the further out in the carriageway the cyclist rode, the less space is received from overtaking vehicles; drivers generally pass closer to a helmeted cyclist; and drivers of buses and heavy goods vehicles pass closer than other types of vehicle. The work did not take account of available carriageway widths or the widths of the passing vehicles. He recommended that the effect of on-road cycle lanes be investigated, and this demands that proper attention is given to available road width.

In order to improve on research into the perception of cycling that had hitherto only considered links, Parkin et al. (2008) used video clips of routes and junctions from the point of view of a cyclist and presented them to cycling and non-cycling commuters. The Risk Ratings for combinations of routes and junctions which mimicked real potential journeys by the respondents were on a scale of 1 (lowest perceived risk) to 10 (highest perceived risk) and were used as the dependent variable in a logistic regression model constrained to lie within the Risk Rating range. The model did not explicitly consider width, but flow passing the cyclist was found to be significant.

The literature suggests no common definition of the disutility associated with cycling: sometimes it is considered on a measure purporting to be a 'level of service', sometimes a 'compatibility' or 'cyclability' index, the components of which include issues connected with safety, effort and pleasure, or it has been considered as a risk rating. There is no commonly emerging functional form for the inclusion of passing distance as a measure of disutility, and the contribution of passing distance to the overall disutility appears to vary between studies. Design standards appear to be based on observed 
passing distances, but there is no correlation suggested between these observed distances and perceived comfort for the cyclist. The effect on passing distance of the presence of a cycle lane needs to be more fully understood.

\section{$3 \quad$ Methodology}

An Archos Helmet Camcorder was attached to the rear rack of a hybrid bicycle (Marin Mill Valley) and fed video images into an Archos 605 MP4 recording device. The camera was mounted securely to the rear rack of the bicycle and angled so that the road to the right of the cyclist could be recorded along with footage of overtaking vehicles, as shown in Figure 2 (left hand rule of the road).

[Insert Figure 2 here]

Calibration was achieved by taking video footage of marks on the ground at distances from 20 millimetres to 2200 millimetres away from the bicycle in increments of 50 millimetres. The footage was viewed on Windows Media Player $11^{\mathrm{TM}}$ and a transparency, placed over the computer screen, was used to create a 'screen ruler' to measure the position of objects in relation to the bicycle. Using footage of overtaking manoeuvres collected whilst cycling on roads both with and without cycle lanes and using the front wheel of the vehicle as a reference point, the proximities of the overtaking vehicles could be established. The instrumented bicycle was checked to ensure that it remained calibrated correctly after each period of data collection. 
There is a degree of natural variation in the lateral positioning of a vehicle within a lane as it travels along a carriageway. This is as a result of the negotiation of horizontal and vertical geometry, variation in width of the carriageway and human variability, and this is the case both for cycle traffic and motor traffic. In order to minimise the degree of variability in the results that would be obtained, the surveyor-cyclist kept as constant a distance from the kerb as possible: with his centre line at 500mm from the kerb and his offside shoulder $800 \mathrm{~mm}$ from the kerb. A precisely measured distance to the kerb could have been provided to the surveyor-cyclist using an ultrasonic distance sensor, with instructions that he attempt to keep the device reading a certain value. It was deemed that the attention paid to this device might have impaired the rider and increased the risk of an accident. Instead, the rider practised cycling on a chalk-drawn cycle lane of width one metre on a private road. Initially, the cycle lane was bi-sected by a solid line but this was subsequently replaced by a dashed line indicating the mid-point of the cycle lane, and more of the markings were removed until the technique had been mastered. A similar technique was employed for use on stretches of road without cycle lanes. Any deviations that remained should cancel themselves out through the collection of a large number of vehicle overtaking proximities.

Using footage of overtaking manoeuvres collected whilst cycling on roads both with and without cycle lanes and using the front wheel of the passing vehicle as a reference point, the proximities of the overtaking vehicles were established. The bicycle was checked to ensure that it was calibrated correctly after each period of data collection. 
Three sites were selected for analysis and had posted speed limits of 30mph, 40mph and 50mph (48kph, 64kph and 80kph). The characteristics of the spread in speed for the roads surveyed is provided in Table 1 . Each site contained stretches of road with and without cycle lane. The sites were all virtually straight and flat in order to eliminate horizontal and vertical geometry variables.

[Insert Table 1 here]

Site 1 (50mph) is on the A6 at Cabus, near Garstang, Lancashire, England. The width of the cycle lane is 1.45 metres with an overall road width of 9.57 metres $^{1}$. In the area without a cycle lane, the overall road width is 9.64 metres. Figure 3 shows the two sites. Site 2 (40mph) is on the A6 at Broughton, north of Preston, Lancashire. The average width of the cycle lane is 1.45 metres with an overall road width of 9.57 metres. In the area without a cycle lane, the overall road width is 9.37 metres. Figure 4 shows the two sites. Site 3 (30mph) is in Westgate, a suburb of Morecambe in Lancashire. The width of the cycle lane is 1.30 metres with an overall road width of 9.45 metres. In the area without a cycle lane, the overall road width is 9.49 metres. Figure 5 shows the two sites.

[Insert Figure 3, 4 and 5 here]

\footnotetext{
${ }^{1}$ The road width and cycle lane width were measured at five locations using a Leica Disto D3 laser meter, allowing an average road width and an average cycle lane width to be calculated. There is little variation in painted cycle lane widths.
} 
The data were collected outside the morning and evening peak periods during daylight at all three sites. The flow of vehicles was intermittent with no pronounced platooning. The overtaking distances of vehicles were taken in 'real life', where gaps between vehicles are uncontrolled. The lateral position of a vehicle following another vehicle relatively closely may be influenced by the leading vehicle. No vehicle data was eliminated on the basis of proximity to the vehicle ahead and hence the analysis accounts for the full sample of vehicle data collected. This is appropriate and provides a valid measure of the mean passing distances for all vehicles on the road.

The experimenters considered the possibilities of including data on traffic passing in the opposite direction at the time of the overtaking manoeuvre. The complexity of obtaining lateral positioning details of vehicles travelling in the opposite direction precluded this data from being collected for this experiment. A helmet mounted camera would have been insufficient to identify the proximity of vehicles travelling in the opposite lane owing to the potential height of nearside lane overtaking vehicles, a bicycle-mounted camera of sufficient height to ascertain such data would have been incongruous and may have influenced driver overtaking-behaviour. The positioning of a camera to record oncoming traffic prior to or post-overtaking was also ruled out for reasons of possible obscuring by vehicles, and the use of a camera in an alternative location would have only enabled a very short section of road to be surveyed from an elevated position making site selection and data collection extremely difficult. The availability of such opposite-direction traffic data would possibly be able to explain some of the variation in passing distance data that is collected. 


\section{$4 \quad$ Analysis}

Vehicles were classified as being of the following types: cars (including sports utility vehicles), van (including medium and large vans), heavy goods vehicles (HGVs) of all types, buses and motorcycles (including mopeds). Analysis of the means and variances of the passing distances shows that the vehicles could be grouped into four categories Cars, Vans, HGVs and Buses and Motorcycles. Table 2 summarises the mean and standard deviation of the passing distances by site ${ }^{2}$.

[Insert Table 2 here]

It is interesting to note that at the two sites on the A6, Cabus and Broughton, the passing distance of cars without a cycle lane is respectively $181 \mathrm{~mm}$ and $68 \mathrm{~mm}$ greater than with a cycle lane and these differences are significant (univariate analysis of variance, $\mathrm{F}=20.831, \mathrm{p}=0.000$ for A6 Cabus and $\mathrm{F}=9.513$, $\mathrm{p}=0.002$ for A6 Broughton). The difference at Westgate of $37 \mathrm{~mm}$ is however not significant $(\mathrm{p}=0.359)$. There are no other significant differences for other vehicle types and this is likely to be due to the sample sizes. It is instructive to note that the passing distances are larger without a cycle lane for every comparison apart from the comparison for HGVs and Buses at the A6, Cabus.

\footnotetext{
${ }^{2}$ We were not able to devise a method of estimating the distance from the cyclist to the wing mirror tip, and hence have used the more precisely definable distance to the tyre-road interface. It is not clear which part of the body work of his or her vehicle a driver may be aware of or considering when completing overtaking manoeuvres and we think that the measured distance to the nearside tyre is a good estimate of passing distance of a vehicle.
} 
The significantly wider passing distance offered by motorists on the A6 at Broughton without a cycle lane is all the more noteworthy when it is realised that the carriageway without the cycle lane is 200 millimetres narrower than the carriageway with the cycle lane.

The passing distance will be influenced by the available width to the motor vehicle driver, with passing distances being smaller on narrower carriageways. The available gap will also vary depending on whether or not traffic is coming towards the overtaking vehicle, a variability which we have not be able to account for in this experiment. Considering a car overtaking the bicyclist on the A6 at Cabus in the condition without a cycle lane, it may be seen that the total gap available in the lane is (9570/2)-800$1819=2166 \mathrm{~mm}$. The proportion of this dimension which the motor vehicle driver leaves between the motor vehicle and the cyclist provides an indicator of the way that the motorist uses the available road space. Table 3 shows the mean passing distance of cars as a proportion of available space in lane.

[Insert Table 3 here]

The mean proportions are all greater than 0.5 and this implies that the motorist is leaving more than half of the available space between the motor car and the cyclist as compared with the distance between the motor car and the centre lane line. No data were collected concerning traffic in the oncoming direction and so it is not possible precisely to determine what proportion of the space between moving vehicles has been 
left between the passing car and the bicycle. The relative gap left for the cyclist compared with the gap left for any oncoming vehicle may be estimated assuming the oncoming vehicle is the same distance from the centre line in the opposing lane. These estimates are also shown in Table 3.

The difference between the proportions on the A6 at Cabus with and without a cycle lane (0.701 and 0.772) is significant ( $\mathrm{p}=0.000)$, as is the difference on the A6 at Broughton $(0.520$ and $0.579, \mathrm{p}=0.000)$. This is not the case at Westgate. These results simply parallel the results based on the measured passing distance, which is to be expected because the widths of neither the roads nor the motor vehicles themselves vary greatly, at least not in comparison with the variation in measured passing distances.

Further inconclusive analysis has been performed to determine the distribution of the passing distances. It was hypothesised that in the circumstance where there is a superabundance of space within the lane, the passing distance would be distributed standard normal, but in cases where the cross-section is tight a skewed distribution would obtain. The data do not support such hypotheses.

\section{$5 \quad$ Discussion}

The data collected provide evidence that motor traffic passes cycle traffic at closer proximities in the presence of a cycle lane 1.45 metres wide on high speed roads (40 $\mathrm{mph}$ and $50 \mathrm{mph}$ ) where the overall carriageway width is of the order of 9.5 metres. No 
significant differences were found on a similar width road with a $30 \mathrm{mph}$ speed limit and a 1.3 metre cycle lane.

The reason for the disparity between the overtaking distances of vehicles at Broughton with the $30 \mathrm{mph}$ speed limit and those at the other sites investigated are likely to be due to the particular characteristics of the sites selected for the study. The Broughton site has more side road junctions and hence there is likely to be greater amount of variability in road positioning amongst motor vehicles within the lane because of pre-positioning for making a turn, or positioning as a consequence of just having made a turn into the road. Observations of behaviour along the road also show that straight through vehicles will also have been avoiding vehicles making turning manoeuvres, for example by taking a line further from the kerb line when a vehicle in front was making a left turn manoeuvre. There are also relatively recently added adjacent facilities for cyclists in parallel but off the carriageway. Drivers may consider those cyclists remaining on the highway sufficiently competent that that they are less likely to make erratic movement towards the centre line (see Walker's helmet study).

The reasons for the significant differences on the two higher speed roads will be linked with the perception of the driver of the road ahead. In the condition with no cycle lane, the cyclist is in the same lane as the motorist and it is incumbent on the motorist then to consciously perform an overtaking manoeuvre. When the cyclist is in an adjacent lane, a cycle lane, the motorist has a clear lane ahead and it is not necessary for an overtaking manoeuvre to be performed. The driver is likely to drive between the two lane lines, the cycle lane line and the road centre line, in a position which is appropriate for the visible 
highway horizontal geometry ahead of the driver. The driver's position within the lane is also likely to be affected by encroachments across the lane lines into the driver's lane by other vehicles and by the presence of obstacles beyond the lane lines and which the driver thinks may require a correction to his or her position within the lane. A cyclist cycling wholly within a 1.45 metre cycle lane, with the cyclists offside shoulder being 650 millimetres beyond the cycle lane line from the point of view of the driver, does not appear to be a circumstance where a driver adopts a position within his or her lane different from the position they would otherwise adopt, that is to say the driver is driving with reference to the lane lines and not to the cyclist.

The findings would suggest that at higher speeds and in the absence of a cycle lane, motor traffic is naturally providing more comfortable passing distance than is created by a 1.45 metre wide cycle lane. Design guidance (DfT, 2008) suggests that cycle lanes should be 2 metres wide on busy roads or where motor traffic is travelling in excess of $40 \mathrm{mph}$. The additional passing distance offered by motor traffic without a lane (less than 200 millimetres in both cases, is not as large as the additional width over and above 1.45 metres offered by a 2 metre cycle lane. However, with a given fixed width of road (broadly 9.5 metres for the two higher speed roads under consideration), it is not self evident that the additional cycle lane width would necessarily provide the same additional passing width as provided in the situation without a cycle lane.

The lack of a significant difference in passing distances between the with and without cycle lane condition on the road with a posted speed limit of 30mph may be due to 
drivers not making a conscious overtaking manoeuvre in the condition without a cycle lane.

The data do not support a view as to what a comfortable passing distance should be and this would require further research considering objective measures of comfort, such as lateral force and noise, as well as self-reported ratings of comfort.

\section{Conclusions}

It may be concluded that in circumstances where a cycle lane is insufficiently wide for the speed of general motor traffic, drivers provide greater passing distances to cyclists on stretches of road without cycle lanes. Cycle lanes therefore do not appear to provide greater space for cyclists in all conditions. The limited data available on different vehicle types suggest that motor vehicle overtaking proximity also varies depending on vehicle type, and this confirms Walker's finding.

These results should encourage further investigation into the effectiveness of cycle lanes in separating cycle traffic from motor traffic. Differences in lateral separation may affect risk of collision, but may equally affect the perception of journey ambience for cyclists, also an important consideration.

Further research could usefully collect larger samples for different vehicle types and consider the effect of different types of cycle lane provision, including mandatory cycle lanes delineated by solid white lines and cycle lanes with coloured surfaces. The effect 
of the presence or absence of a central white line dividing the two halves of the carriageway would also be interesting to compare. It would also be of value to develop methodologies for measuring the position of traffic passing in the opposite direction to travel, which traffic, when present, is likely to reduce the passing distance between same direction motor traffic and cycle traffic and hence account for some of the variation in the data collected as part of the experiment reported here.

\section{Acknowledgement}

The authors acknowledge the financial support and other support provided by John Meudell and Chris Peck of CTC and the support and guidance of Alasdair Simpson of Lancashire County Council.

\section{References}

Basford, L., Reid, S., Lester, T., Thomson, J., Tolmie, A. (2002) Drivers’ perception of cyclists. TRL Report TRL549. Transport Research Laboratory, Crowthorne.

CROW (1993) Sign Up for the Bike: Design Manual for a Cycle friendly Infrastructure. Netherlands: Centre for Research and Contract Standardisation in Civil and Traffic Engineering.

CROW (2006) Design manual for bicycle traffic. Netherlands: Centre for Research and Contract Standardisation in Civil and Traffic Engineering.

DfT (2008) Cycle Infrastructure design. Local Transport Note 02/08. October 2008. Department for Transport, London, www.dft.gov.uk 
Davies, D.G., Halliday, M.E., Mayes, M. and Pocock, R.L. (1997) Attitudes to cycling: a qualitative study and conceptual framework. TRL Report 266. Transport Research Laboratory. Crowthorne.

FHWA (1975) Safety and locational criteria for bicycle facilities. User manual 1: Bicycle facility location criteria. FHWA-RD-75-113. Federal Highway Administration, US Department of Transportation, Washington DC.

FHWA (1999) Bicycle lanes versus wide curb lanes: operational and safety findings and countermeasure recommendations. FHWA-RD-99-035. Federal Highway Administration, US Department of Transportation. www.fhwa.dot.gov Gardner, G. (1998) Transport implications of leisure cycling. TRL Report TRL347. Transport Research Laboratory. Crowthorne.

Guthrie, N., Davies, D.G. and Gardner, G. (2001) Cyclists’ assessments of road and traffic conditions: the development of a cyclability index. TRL Report 490. Transport Research Laboratory. Crowthorne.

Harkey, D.L., Reinfurt, D.W., and Knuiman, M. (1998) Development of the Bicycle Compatibility Index. Transportation research record, 1636, Paper No.98-1073. Henson, R.R., Skinner, A. and Georgeson, N. (1997) Analysis of cycling deterrence factors in Greater Manchester. Proceedings of Velo City the $10^{\text {th }}$ International Bicycle Planning Conference. Barcelona, Spain. Lancashire County Council (2005) Lancashire - the cyclists' county. A code for planning, designing and maintaining roads and tracks for cyclists. Lancashire County Council Environment Directorate, Preston. http://www.lancashire.gov.uk Landis, B.W., Vattikuti, V.R., Brannick, M.T. (1997) Real-time human perceptions toward a bicycle level of service. Transportation Research Record 1578 
Owens, P. (2005) The effect of cycle lanes on cyclists’ road space.

www.warringtoncyclecampaign.co.uk

Parkin, J., Wardman, M. and Page, M. (2007) Models of perceived cycling risk and route acceptability. Accident Analysis and Prevention Vol. 39 No. 2 pp364-371. doi:10.1016/j.aap.2006.08.007.

Sorton, A. and Walsh, T. (1994) Bicycle stress level as a tool to evaluate urban and suburban bicycle compatibility. Transportation research record 1438, pp17-24. Stone, M. and Broughton, J. (2003) Getting off your bike: cycling accidents in Great Britain in 1990-1999. Accident analysis and prevention 35 (2003) pp549-556 Walker, I. (2007) Drivers overtaking bicyclists: objective data on the effects of riding position, helmet use, vehicle type and apparent gender. Accident Analysis and Prevention Vol. 39 Part 2, pp417-425 doi:10.1016/j.aap.2006.08.010

Figure 1 Lancashire County Council design guidance on width at 30mph

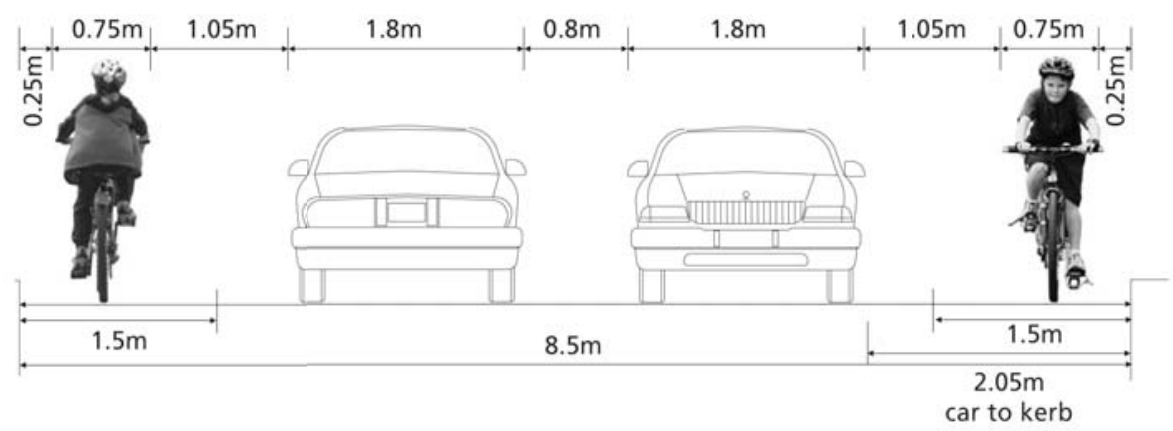

Figure 2 The survey bicycle and equipment 


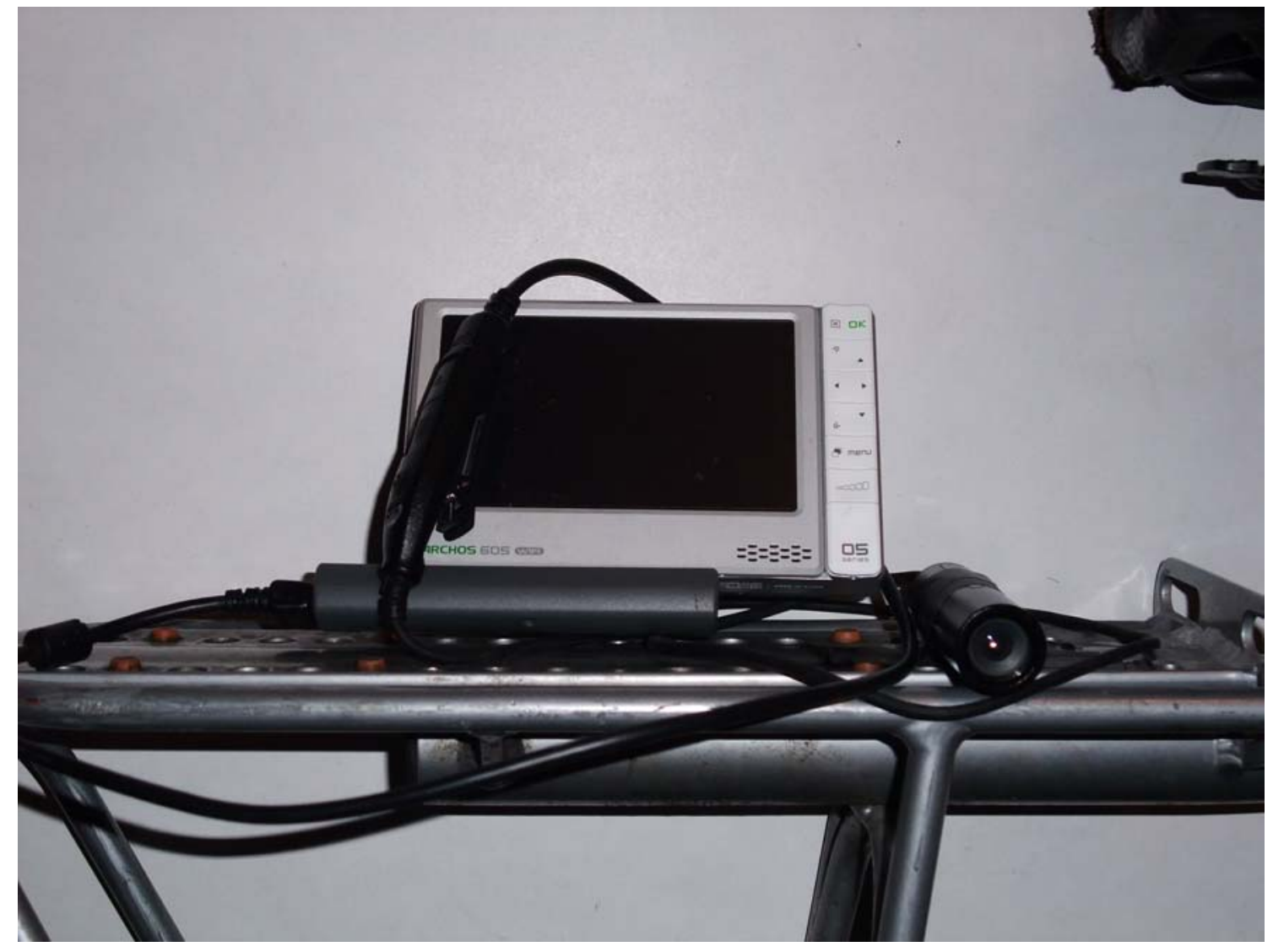

Note: the saddle is in the top right of the frame and the cylindrical camera is mounted to the right of the data collection device on the rear pannier.

Figure $3 \mathrm{A6}$ at Cabus, 50mph site (Site 1)

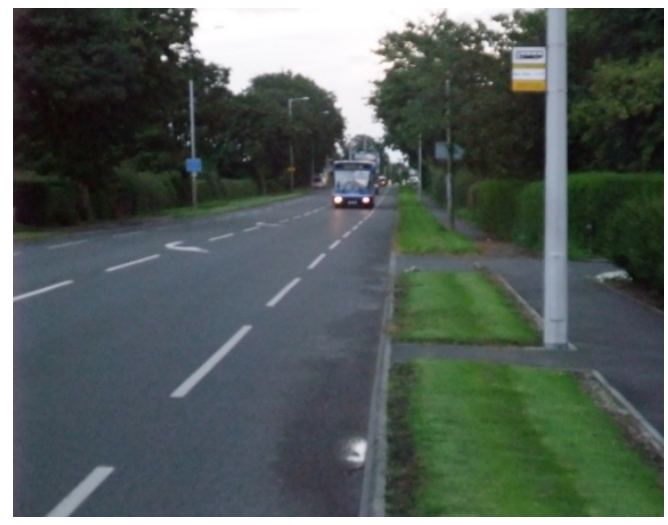

With cycle lane

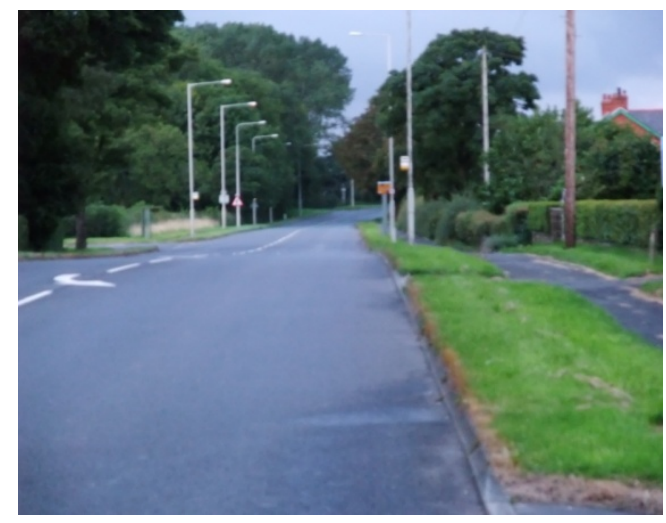

Without cycle lane 
Figure 4 A6, Broughton, 40mph site (Site 2)

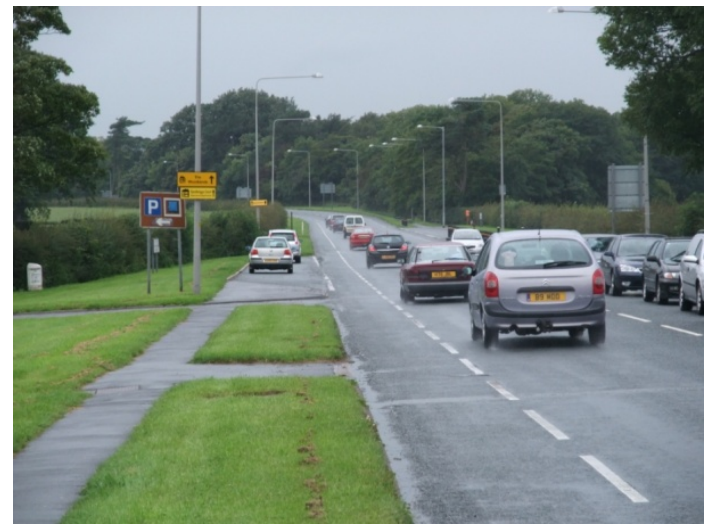

With cycle lane

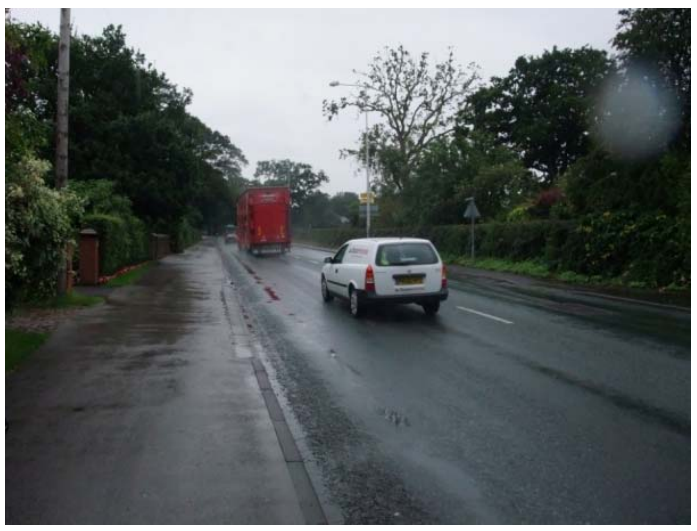

Without cycle lane

Figure 5 Westgate, Morecambe, 30mph site (Site 3)

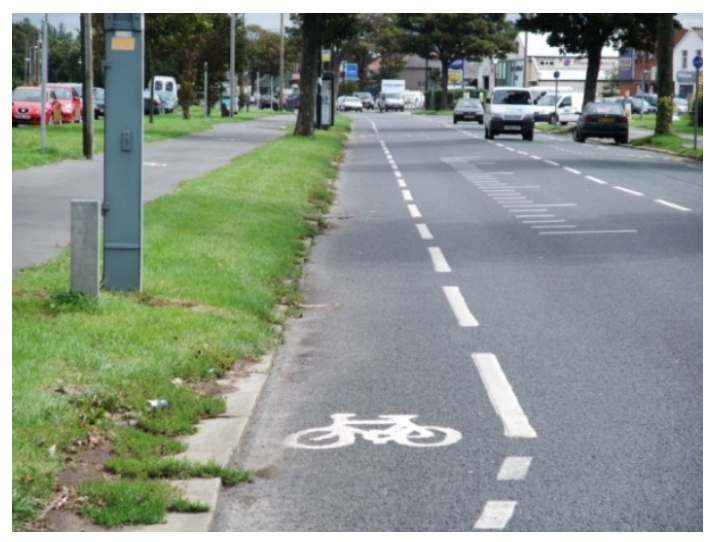

With cycle lane

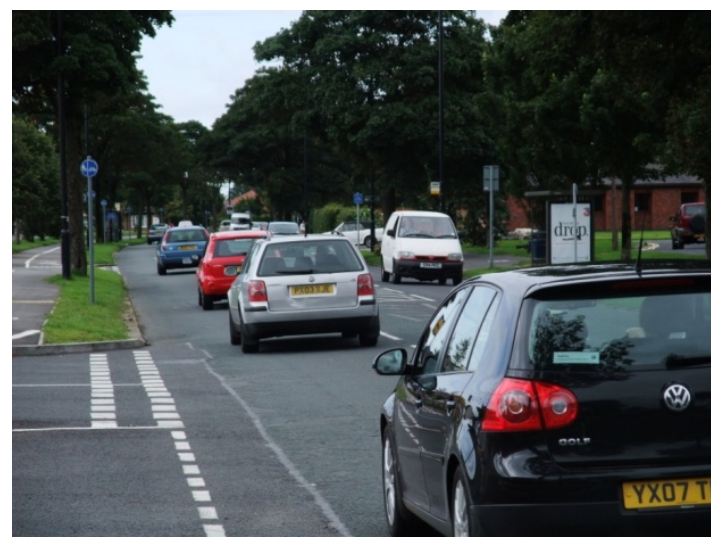

Without cycle lane 
Table 1 Characteristics of the spread of speed of the surveyed roads
Annual
Average
Daily
Traffic

A6 Cabus, 50mph with cycle lane 58,899

A6 Cabus, $50 \mathrm{mph}$, without cycle lane

62,886

0.5

0.3

0.1

A6 Cabus, 50 mph, without cycle lane

A6, Broughton 40mph, with cycle lane

A6, Broughton, 40mph, Southbound

0.3

Percentage over $40 \mathrm{mph}$

\begin{tabular}{rcccc} 
& $0 \%$ & $25 \%$ & $37.5 \%$ & $50 \%$ \\
8,840 & $100 \%$ & $0 \%$ & $0 \%$ & $0 \%$ \\
11,554 & $100 \%$ & $0 \%$ & $0 \%$ & $0 \%$ \\
\multicolumn{4}{c}{ Percentage over $30 \mathrm{mph}$}
\end{tabular}

Percentage over $30 \mathrm{mph}$

Westgate, $30 \mathrm{mph}$, With cycle lane

$0 \% \quad 10 \% \quad 15 \% \quad 20 \%$

Westgate, $30 \mathrm{mph}$, without cycle lane

$\begin{array}{lllll}216,581 & 51.4 & 2 & 2.4 & 2.3\end{array}$

Source: Lancashire County Council. NB Speed was recorded in excess of $60 \mathrm{mph}$ for the $50 \mathrm{mph}$ section and no speeding was recorded on the $40 \mathrm{mph}$ section. 
Table 2 Mean passing distance and median vehicle width by class

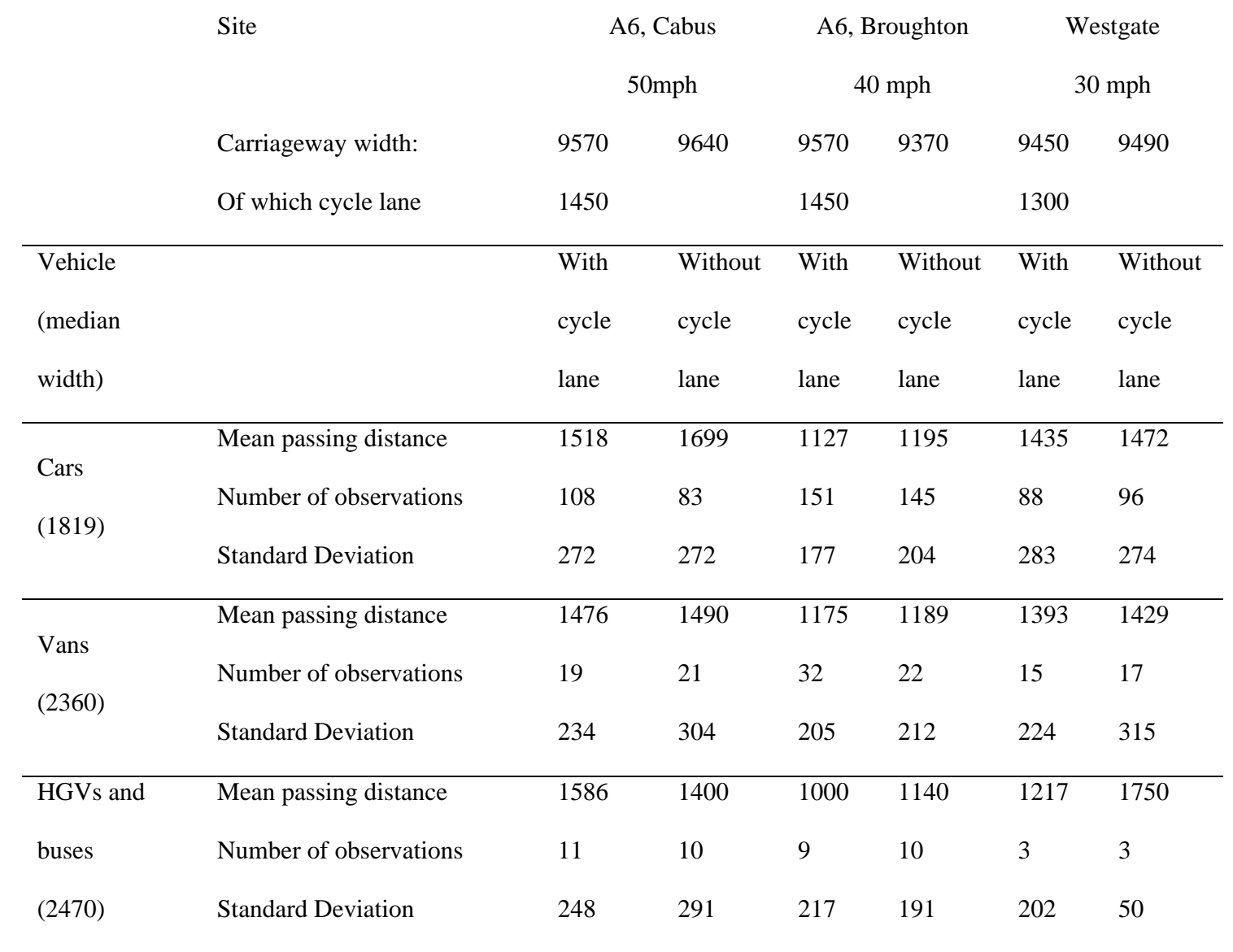

Note: all dimensions in millimetres 


\section{Table 3 Mean passing distance of cars as a proportion of available space in lane}

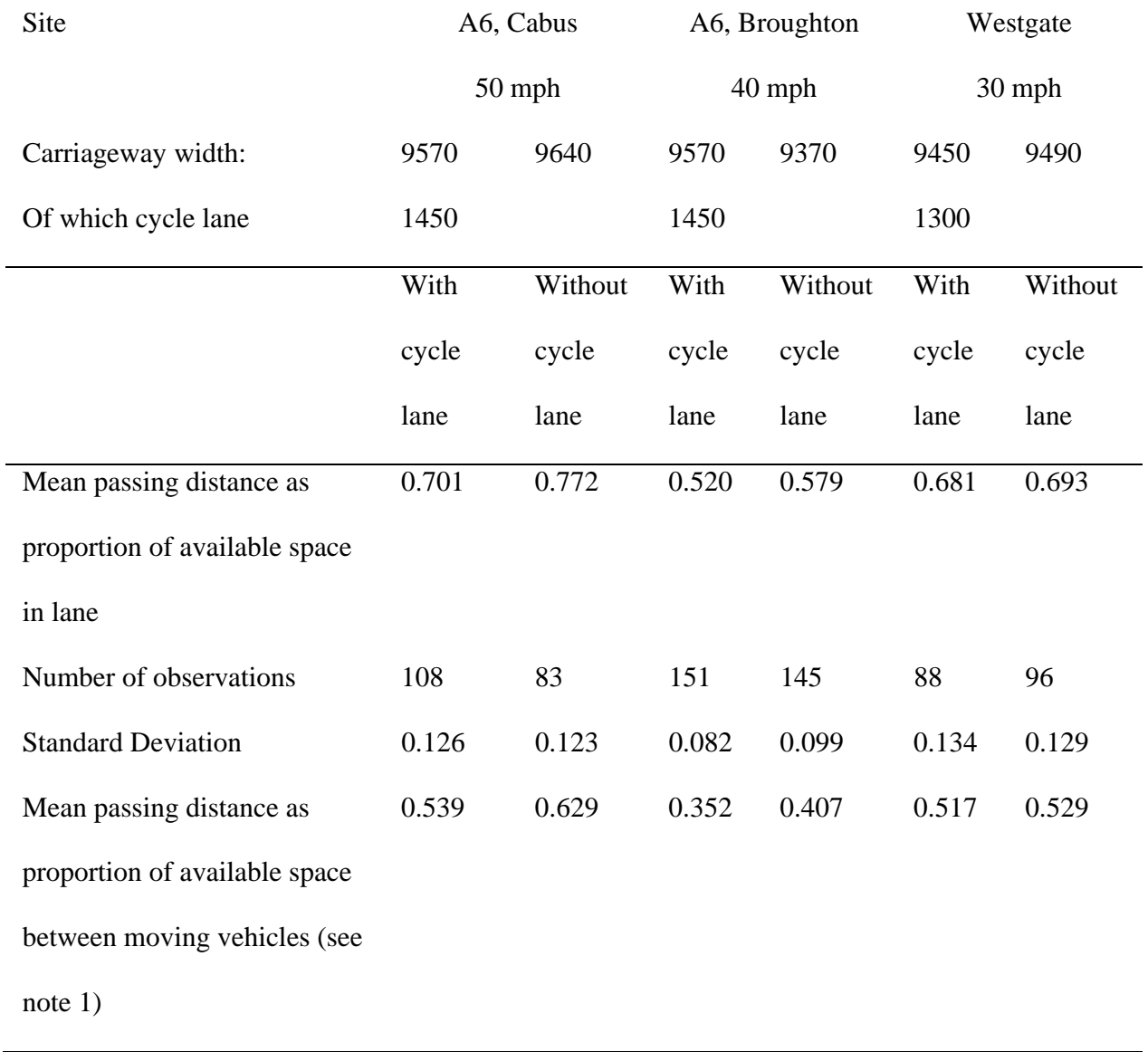

\section{Notes}

1 Estimated assuming an oncoming vehicle is the same distance from the centre line in the opposing lane. 